\title{
Identification of Allergic Disease Among Users of Antihistamines
}

\author{
SHERYL L. SZEINBACH, PhD; P. BROCK WILLIAMS, PhD; PIETER MUNTENDAM, MD; and RICHARD D. O'CONNOR, MD
}

\begin{abstract}
OBJECTIVE: Patients exhibit a multitude of symptoms that may or may not be allergy related. In this study, we examined the consistency between results obtained by a multiallergen-specific immunoglobulin $\mathrm{E}(\mathrm{IgE})$ test and frequent use (3 months or more) of prescribed antihistamines.

METHODS: A retrospective examination of 1-year prescription claims records from January 1, 2000, through December 31, 2000, for 4,643 patients enrolled in a 115,000-member managed care organization who received 1 or more prescriptions for an oral antihistamine (loratadine, fexofenadine, or cetirizine).

RESULTS: A total of 1,343 health plan enrollees who received an oral antihistamine prescription were continuously enrolled during the year 2000 and diagnosed with allergic rhinitis. Of these patients, $246(18 \%)$ consented to a multiallergen-specific $\lg \mathrm{E}$ test, and 159 patients $(64.6 \%)$ had a negative $\lg \mathrm{E}$ test result. A total of 163 patients were classified as frequent antihistamine users (3 or more antihistamine prescriptions), and 101 (62.0\%) of these patients had negative test results. Our study demonstrated no relation between prescribed antihistamine use and patient sensitization status.
\end{abstract}

CONCLUSIONS: Only $35.4 \%$ of the patients who used an oral antihistamine and were diagnosed with an allergy tested positive to the multiallergen-specific $\lg \mathrm{E}$ test, and only $38 \%$ of the patients with records of frequent antihistamine use and who were diagnosed as allergic tested positive to the multiallergen-specific $\lg \mathrm{E}$ test. Apparently, there are patients taking medications prescribed for allergic rhinitis who are, in fact, not allergic, which is both wasteful economically and not indicated medically. Additional evaluation may be advisable to support the clinical diagnosis of allergy for patients presenting with allergy-like symptoms who use antihistamines frequently.

KEYWORDS: Allergic rhinitis, Multiallergen-specific lgE testing, Low-sedating antihistamines

J Manag Care Pharm. 2004;10(3):234-238

\section{Authors}

SHERYL L. SZEINBACH, PhD, is professor, Ohio State University, College of Pharmacy, Columbus; P. BROCK WILLIAMS, PhD, is clinical professor, University of Missouri Medical School, Kansas City; PIETER MUNTENDAM, MD, is director, biopharma and healthcare practice, netNumina, Cambridge, Massachusetts; RICHARD D. O'CONNOR, MD, is director of quality management, Sharp ReesStealy Medical Group, San Diego, California.

AUTHOR CORRESPONDENCE: Sheryl L. Szeinbach, PhD, Professor, Department of Pharmacy Practice and Administration, College of Pharmacy,

Ohio State University, Columbus, OH 43210-1291. Tel: (614) 688-4249;

Fax: (614) 292-1335; E-mail: szeinbach.1@osu.edu

Copyright $\odot$ 2004, Academy of Managed Care Pharmacy. All rights reserved. ymptoms compatible with allergic (immunoglobulin E [IgE] mediated) disease are common and have multiple $\checkmark$ etiologies. Thus, effective treatment depends on clinical evaluation and an accurate diagnosis. According to the American Academy of Allergy, Asthma, and Immunology (AAAAI), treatment measures such as allergen avoidance and pharmacotherapy should be based on positive history and diagnostic testing. ${ }^{1}$ Although that report emphasizes the important role of professional referral and skin testing, the use of multiallergen-specific IgE testing by family physicians has been acknowledged as an accurate tool, useful in identifying specific allergen sensitivities and helpful in focusing further investigation and referral. ${ }^{2,3}$ With allergy prevalence estimates of $10 \%$ to $30 \%$, antihistamine drugs such as fexofenadine (Allegra), loratadine (e.g., Claritin), and cetirizine (Zyrtec), have gained widespread acceptance as a strategy to help patients cope with allergic symptoms. ${ }^{4,5}$

Positive benefits of prescribed antihistamines for allergic rhinitis include increased airway caliber, improved breathing, and significantly reduced symptoms. ${ }^{6}$ Other studies suggest that medications prescribed to treat allergic rhinitis may alleviate symptoms of asthma. ${ }^{7}$ While these medications appear to reduce symptoms and improve patient health, consideration must be given to their total cost, estimated at $\$ 8.4$ billion per year. ${ }^{8}$ For some patients, however, the use of allergy medication may not be effective or offer only a short-term solution for an ongoing problem. ${ }^{9}$ For example, the authors in one study asserted that although these medications may alleviate symptoms, an accurate diagnosis suggests more appropriate clinical management, less frequent medication changes, and improved quality of life. ${ }^{10}$

Decisions to prescribe these medications are usually predicated on clinical evaluation, including patient history and perhaps some diagnostic testing. In the process of patient evaluation, patient history can be subjective and influenced by perceptual interpretation with respect to clinical experience and expectations. Moreover, pertinent information may be selectively filtered or overlooked in the communication process. Besides patient history, diagnostic tools include avoidance, specific allergen challenges, medication trials, and those that indicate immunological sensitization. ${ }^{11}$ Successful medication trials with antihistamines are often interpreted as proof of an allergic etiology even though their activity is rather nonspecific. An example of a test that indicates sensitization is the multiallergen-specific IgE test, which contains about 15 different common allergens that identify approximately $98 \%$ of the patients with allergic rhinitis. This specific IgE test is highly specific and selective for IgE antibodies to a mixture of the most prevalent inhalant allergens. ${ }^{12}$ 
Only recently has evidence surfaced to suggest that patient history and symptoms may not align well with the results obtained from diagnostic tests such as skin testing or multiallergen-specific IgE testing. In one study, the accuracy of the diagnosis of a patient for a specific allergic condition by history alone compared with concordant skin testing and specific $\operatorname{IgE}$ measurements rarely exceeded $50 \%$ and, in some cases, was below 25\%. ${ }^{13}$ Given this potential for discrepancy between history and true diagnosis, questions arise regarding the existence of similar discrepancies between prescribed antihistamine use and multiallergen-specific IgE testing.

In this study, we investigate whether the patterns of prescribed antihistamine use in a managed care facility were consistent with results obtained from a multiallergen-specific IgE test for allergy. Specifically, the UniCAP Phadiatop is a single laboratory test designed to determine the presence or absence (e.g., positive or negative) of specific IgE to a variety of common inhalant allergens (e.g., grass, ragweed, cat, and mite). ${ }^{14}$ In this study, the cut-off point for positivity for the specific IgE assays was $0.35 \mathrm{kUA} / \mathrm{L}$, with test sensitivity and specificity reported at $100 \% .^{14,15}$ Test results were categorized as either positive or negative.

\section{Methods}

Prescription claim records for 4,643 patients enrolled in a 115,000-member health plan located in the southeast United States were examined retrospectively by 2 pharmacists to identify patients who received at least 1 prescription for a low-sedating antihistamine (LSA) in tablet or capsule form (cetirizine $5 \mathrm{mg}$ or $10 \mathrm{mg}$, fexofenadine $60 \mathrm{mg}$, loratadine $10 \mathrm{mg}$, and all combinations with pseudoephedrine). Of these 4,643 patients, there were 1,343 patients with a diagnosis of allergic rhinitis (ICD-9-CM 477.0, 477.8, and 477.9 for pollen, other allergens, and unspecified, respectively). Antihistamine use was defined 


\begin{tabular}{|c|c|c|c|c|}
\hline $\begin{array}{rr}\text { TABLE 1 Cro } \\
& \text { Mu } \\
& \text { and }\end{array}$ & $\begin{array}{l}\text { ibulation of Labo } \\
\text { ergen Specific IgE } \\
\text { quent Antihistan }\end{array}$ & $\begin{array}{l}\text { rato } \\
\text { Ees } \\
\text { nine }\end{array}$ & $\begin{array}{l}\text { Result } \\
\text { se } 1 Y\end{array}$ & $\begin{array}{c}( \pm) \\
\text { s/No) }\end{array}$ \\
\hline & & Freque & t Use & \\
\hline Screening Result: $\dagger$ & & No & Yes & Total \\
\hline Negative test & Count & 58 & 101 & 159 \\
\hline & $\%$ within nonallergic & 36.5 & 63.5 & 100.0 \\
\hline & $\%$ within frequent use & 69.9 & 62.0 & 64.6 \\
\hline & $\%$ of total & 23.6 & 41.1 & 64.6 \\
\hline Positive test & Count & 25 & 62 & 87 \\
\hline & $\%$ within allergic & 28.7 & 71.3 & 100.0 \\
\hline & $\%$ within frequent use & 30.1 & 38.0 & 35.4 \\
\hline & $\%$ of total & 10.2 & 25.2 & 35.4 \\
\hline Nonallergic and allergic & Count & 83 & 163 & 246 \\
\hline & $\%$ of total & 33.7 & 66.3 & 100.0 \\
\hline $\begin{array}{l}\text { * Frequent antihistamine } \\
\text { antihistamines during th } \\
+ \text { Screening test results ava } \\
\text { with the multiallergen-sp } \\
\text { Chi-square test }\left(X{ }^{2}=1.5\right. \\
\text { immunoglobulin } E \text {. }\end{array}$ & $\begin{array}{l}\text { fined as } 3 \text { or more prescrip } \\
\text { tinuous } 12 \text {-month enrollme } \\
\text { only for those who were lal } \\
\text { IgE test. } \\
\text {.225) for the convenience }\end{array}$ & $\begin{array}{l}\text { ptions } f \\
\text { ent peri } \\
b \text { tested. } \\
\text { sample }\end{array}$ & $\begin{array}{l}\text { low-sec } \\
\text { ill tests } \\
V=246\end{array}$ & $\begin{array}{l}\text { ting } \\
\text { IgE is }\end{array}$ \\
\hline
\end{tabular}

as infrequent if fewer than 3 prescriptions for LSAs during the 12-month period from January 1, 2000, to December 31, 2000.16

Once these patients were identified, a convenience sample yielded 246 patients who completed a consent form and desired confirmation of their allergy diagnosis with a free multiallergenspecific IgE test (Phadiatop by Pharmacia Diagnostics, Current Procedural Terminology Code [CPT] 86005) ${ }^{17,18}$ (Figure 1). Patients were offered a mailed summary of their survey responses and, based on these replies, personalized allergy-management information.

Age and gender were the only demographic data available for the study participants, and there was not a significant difference for age or gender between the convenience sample and the plan enrollees who used at least $1 \mathrm{LSA}(\mathrm{N}=1,343$; average age $=43.65$ years $[11.7 \mathrm{SD}]$ for plan enrollees versus $\mathrm{N}=246$; age $=45.02$ years $[11.4 \mathrm{SD}]$ for the convenience sample). The chi-square test of independence was used to assess differences between infrequent and frequent users of prescribed LSAs. Values of $P<0.05$ for a 2-tailed test were considered significant.

\section{Results}

Of the 163 frequent LSA users, 62 (38\%) had evidence of specific IgE that would be consistent with a diagnosis of allergy, and $30.1 \%$ (25 of 83 ) of infrequent users also had similar evidence of specific IgE. Results from the chi-square statistical test revealed no significant difference between the observed and expected frequencies among patients undergoing specific $\operatorname{IgE}$ testing and prescribed LSA use $(\chi 2=1.5 ; P \leq 0.225)$. Thus, our hypothesized relation between prescribed antihistamine use and sensitization status was not supported. However, further examination of the data in Table 1 revealed that $64.6 \%$ (159 of 246) of the laboratory-tested group did not have significant levels of specific IgE (the cut-off for positivity for the specific IgE assays was $0.35 \mathrm{kU}_{\mathrm{A}} / \mathrm{L}$ ), and $63.5 \%$ (101 of 159) of these patients were classified as frequent LSA users over the last year. Stated differently, approximately two thirds of those patients with records of frequent LSA use were tested as negative for specific IgE.

\section{Discussion}

The initial clinical diagnosis of an allergic condition was supported for $35.4 \%$ of the patients who had the multiallergen-specific IgE test. Although the treatment of rhinitis with antihistamines is often used to provide diagnostic evidence of an allergic etiology, it has been estimated that as many as $50 \%$ of patients with rhinitis may not have allergic rhinitis. ${ }^{19,20}$ Thus, in some situations, short-term or intermittent use of these medications is warranted to treat conditions such as nasal congestion, rhinorrhea, sneezing, itching, and hyposmia. However, frequent use (3 months or more) of prescribed antihistamines would suggest the need for more specific evaluation or additional follow-up.

The lack of a significant difference in frequent antihistamine use and the presence or absence of inhalant allergy in this patient population suggest that routine history and physical examination may not always provide accurate evidence to discern allergic from nonallergic rhinitis. ${ }^{5}$ Considering that the results of this study are consistent with findings from previous reports of confirmed allergy $(43 \%, \mathrm{n}=975),{ }^{21,22}$ our findings suggest the need for more extensive patient evaluation criteria. Although patients provide a comprehensive overview of their current health status, additional opportunities exist for clinicians in patient screening and evaluation. For example, patients who present with multiple allergic-like symptoms would undergo preliminary evaluation by trained clinicians and practitioners. Decision protocols can be developed and standardized to ascertain whether perceptual differences in judgment have possibly influenced conclusions drawn from the patient history and evaluation. ${ }^{13}$ After examining patient history and evidence of allergic etiology, or patients appear unresponsive to medications, objective tests such as the multiallergen-specific IgE test may be performed.

At the time of this study, loratadine was available only by prescription, but the availability of loratadine over the counter (OTC) at year-end 2002 begs examination of the means to attain the optimum cost benefit from verification of true allergy in frequent users of antihistamines. While OTC loratadine costs less than $\$ 20$ per month of therapy, most drug plans in managed care organizations (MCOs) cover prescription oral antihistamines that have average wholesale prices that range from $\$ 75$ to $\$ 105$ for a 30-day supply. ${ }^{23}$ The average price paid per spe- 
cific IgE determination ranges from $\$ 10$ to $\$ 12$ per allergen ( $\$ 7.23$ for Medicare). The Medicare median patient charge for allergen testing, which includes 12 to 16 profile allergens and total IgE (\$20) was approximately $\$ 150$ to 175 per profile and ranged from $\$ 50$ to $\$ 500$, depending on the type of test (e.g., skin, blood) and the number of allergens evaluated. ${ }^{24}$ Although these costs, to some extent, may be covered by a third-party plan, patients, providers, and MCOs should evaluate short-term and long-term benefits of serum allergen testing.

From a managed care perspective, optimal strategies for therapy would begin by accurately identifying patients who would benefit from specific IgE testing. Results from this study suggest that confirmation of allergic disease may be more complex, perhaps involving the cooperation of both family physicians and allergists. Primary care physicians might perform initial evaluation, testing, and treatment involving the short-term use of antihistamines and, with patients, evaluate patient responsiveness to drug therapy. Persistent or more-severe symptoms may require further evaluation and referral. Allergy testing may be more beneficial when patients are stratified by severity and persistence of allergy symptoms, magnitude of direct costs (e.g., physician visits, oral antihistamines), and indirect costs (e.g., diminished productivity). These suggestions present opportunities for managed care physicians and pharmacists to work together efficiently to create an environment to improve patient management through initiatives that focus on diagnostic accuracy. Hence, consideration should be given to the additional benefits of testing and the contribution that appropriate prescribing would make toward improving patient outcomes and possibly reducing health care and social costs.

\section{Limitations}

The extent to which patients are affected by allergic rhinitis may be a function of seasonal fluctuations characteristic of the geographic region (southeastern United States) of this MCO. Additionally, survey completion was not designed to necessarily coincide with the annual period during which symptoms were experienced. Hence, the absence of particular symptoms at that time did not preclude the presence of seasonal allergic rhinitis. However, seasonal affects may be of no consequence since the IgE test is unaffected by antihistamine use. Moreover, the presence of IgE is not affected by the season in which the test is performed.

\section{Conclusions}

By far, the most common-but not only-reason for prescribing LSAs is for symptoms with a suspected allergic etiology. Our data suggest that either LSAs are prescribed indiscriminately or that the sequencing of testing and treatment needs further evaluation. Notwithstanding consideration of medication side effects, economic considerations, and the potential for escalating costs associated with the advent of more expensive allergy treatment options (e.g., leukotriene receptor antagonists, anti$\mathrm{IgE}$ ), assuring the existence of allergic etiology may be more beneficial to patients (e.g., reduced office visits, improved quality of life) and increasingly important to managed care providers. Practitioners and clinicians might use objective means such as multiallergen-specific IgE testing in conjunction with other evidence such as patient symptoms and history to confirm the allergic basis of disease.

\section{DISCLOSURES}

Funding for this study was provided by an unrestricted grant from Pharmacia Corporation and was obtained by author Pieter Muntendam. Results from this study were presented at the American College of Osteopathic Family

Physicians (ACOFP) Meeting, Philadelphia, Pennsylvania, March 28, 2001, and at the Aspen Allergy Conference, Aspen, Colorado, July 26, 2001. Author Sheryl L. Szeinbach served as principal author of the study. Study concept and design were contributed primarily by Szeinbach and Muntendam. Analysis and interpretation of data were contributed by Szeinbach and authors P. Brock Williams and Richard D. O'Connor. Drafting of the manuscript was primarily the work of Szeinbach and Williams, and its critical revision was the work of all authors. Statistical expertise was contributed by Szeinbach and Williams, and administrative, technical, and/or material support was provided by Szeinbach and Muntendam.

\section{REFERENCES}

1. American Academy of Allergy, Asthma, and Immunology. The Allergy Report. Milwaukee, WI: AAAAI; 2001.

2. Selner JC, Sullivan TJ, Ahlstedt S, et al. Current issues relating to in vitro testing for allergen- specific IgE: a workshop report. Ann Allergy Asthma Immunol. 1999;82:407-12.

3. Emanuel IA. In vitro testing for allergy diagnosis—comparison of methods in common use. Otolaryngolog Clin North Am. 1998;31:27-33.

4. National Institute for Health Care Management. Prescription drug expenditures in 2000: the upward trend continues. Washington, DC: NIHCM; 2001: $1-24$.

5. www.ahrq.gov. Management of allergic and nonallergic rhinitis. Evidence report/technology assessment: Number 54. July 22, 2003.

6. Grant AJ, Nicodemus CF, Findlay SR, et al. Clinical aspects of allergic disease: cetirizine in patients with seasonal rhinitis and concomitant asthma: prospective, randomized, placebo-controlled trial. J Allergy Clin Immunol. 1995; $95: 923-32$

7. Crystal-Peters J, Neslusan C, White A. An investigation of allergic rhinitis, asthma, and medication use in a privately insured population. J Manag Care Pharm. 2001;7(4):287-91.

8. IMS Health Data. March 2003.

9. Naclerio RM. Drug therapy: allergic rhinitis. N Engl J Med. 1991;325:860-69.

10. Berger WE, Shoheiber O, Ledgerwood GL, Cannon E, Giaquinta DB. New challenges to old standards in the treatment of rhinitis. J Manag Care Pharm. 2001;7(2):S2-S13.

11. Practice parameters for allergy diagnostic testing. Ann Allergy Asthma Immunol. 1995; 75:543-625.

12. Pastorello EA, Icorvaia C, Ortolani C, et al. Studies on the relationship between the level of specific $\operatorname{IgE}$ antibodies and the clinical expression of allergy: 1. Definition of levels distinguishing patients with symptomatic from patients with asymptomatic allergy to common aeroallergens. J Allergy Clin Immunol. 1995;96:580-87.

13. Williams PB, Ahlstedt S, Barnes JH, Soderstrom L, Portnoy J. Are our impressions of allergy test performance correct? Ann Allergy Asthma Immunol. 2003;91:26-33. 
14. Williams PB, Siegel C, Portnoy J. Efficacy of a single diagnostic test for sensitization to common inhalant allergens. Ann Allergy Asthma Immunol. 2001;86:196-202.

15. Nalebuff DJ. In vitro testing methodologies. Evolution and current status. Otolaryngol Clin North Am. 1992;25:27-42.

16. American Academy of Allergy Asthma and Immunology Aeroallergen Network. Available at: www.aaaai.org/nab. Accessed May 15, 2003.

17. Williams PB, Barnes, JH, Szeinbach SL, Sullivan TJ. Analytic precision and accuracy of commercial immunoassay for specific IgE: establishing a standard. J Allergy Clin Immunol. 2000;105:1221-30.

18. Szeinbach, SL, Barnes, JH, Sullivan TJ, Williams PB. Precision and accuracy of commercial laboratories' ability to classify positive and/or negative allergen-specific IgE rsults. Ann Allergy Asthma Immunol. 2001;86:1-9.

19. Dykewicz MS, Fineman S, Skoner DP, et al. Diagnosis and management of rhinitis: complete guidelines of the Joint Task Force on Practice Parameters in Allergy, Asthma, and Immunology. Ann Allergy Asthma Immunol. 1998;81:478518.
20. Ciprandi G, Ricca V, Tosca M, Landi M, Passalacqua G, Canonica GW. Continuous antihistamine treatment controls allergic inflammation and reduces respiratory morbidity in children with mite allergy. Allergy. 1999; 54:358-65

21. Eriksson NE. Allergy screening with Phadiatop and CAP Phadiatop in combination with a questionnaire in adults with asthma and rhinitis. Allergy. 1993;48:602-07.

22. Settipane RA, Lieberman P. Update on nonallergic rhinitis. Ann Allergy Asthma Immunol. 2001;86:494-507.

23. Cohen HE, ed., medical economics. Drug Top Redbook. 2004.

24. Poon AW, Goodman CS, Rubin RJ. In vitro and skin testing for allergy: comparable clinical utility and costs. Am J Manag Care. 1998;4(7):969-85. 